\title{
Importance of basal processes in simulations of a surging Svalbard outlet glacier
}

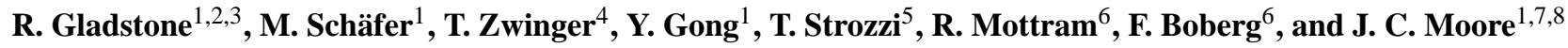 \\ ${ }^{1}$ Arctic Centre, University of Lapland, Rovaniemi, Finland \\ ${ }^{2}$ VAW, Eidgenossische Technische Hochschule Zürich, ETHZ, Switzerland \\ ${ }^{3}$ Antarctic Climate and Ecosystems Cooperative Research Centre, University of Tasmania, Hobart, Tasmania, Australia \\ ${ }^{4} \mathrm{CSC}$ - IT Center for Science Ltd., Espoo, Finland \\ ${ }^{5}$ Gamma Remote Sensing and Consulting AG, Gümligen, Switzerland \\ ${ }^{6}$ Danish Meteorological Institute, Copenhagen, Denmark \\ ${ }^{7}$ Department of Earth Sciences, Uppsala University, Uppsala, Sweden \\ ${ }^{8}$ College of Global Change and Earth System Science \& State Key Laboratory of Remote Sensing Science, Beijing Normal \\ University, Beijing, China
}

Correspondence to: R. Gladstone (rupertgladstone1972@gmail.com) or J. C. Moore (john.moore.bnu@gmail.com)

Received: 8 November 2013 - Published in The Cryosphere Discuss.: 9 December 2013

Revised: 15 June 2014 - Accepted: 17 June 2014 - Published: 4 August 2014

\begin{abstract}
The outlet glacier of Basin 3 (B3) of Austfonna ice cap, Svalbard, is one of the fastest outlet glaciers in Svalbard, and shows dramatic changes since 1995. In addition to previously observed seasonal summer speed-up associated with the melt season, the winter speed of B3 has accelerated approximately fivefold since 1995 . We use the Elmer/Ice full-Stokes model for ice dynamics to infer spatial distributions of basal drag for the winter seasons of 1995 , 2008 and 2011. This "inverse" method is based on minimising discrepancy between modelled and observed surface velocities, using satellite remotely sensed velocity fields. We generate steady-state temperature distributions for 1995 and 2011. Frictional heating caused by basal sliding contributes significantly to basal temperatures of the B3 outlet glacier, with heat advection (a longer-timescale process than frictional heating) also being important in the steady state.

We present a sensitivity experiment consisting of transient simulations under present-day forcing to demonstrate that using a temporally fixed basal drag field obtained through inversion can lead to thickness change errors of the order of $2 \mathrm{~m}$ year $^{-1}$. Hence it is essential to incorporate the evolution of basal processes in future projections of the evolution of B3. Informed by a combination of our inverse method results and previous studies, we hypothesise a system of processes and feedbacks involving till deformation and basal hydrology
\end{abstract}

to explain both the seasonal accelerations (short residence time pooling of meltwater at the ice-till interface) and the ongoing interannual speed-up (gradual penetration of water into the till, reducing till strength).

\section{Introduction}

Austfonna (ASF) is a large (ca. $8000 \mathrm{~km}^{2}$ ) ice cap in the Svalbard Archipelago. ASF is divided into a number of drainage basins. The outlet glacier of one of these basins, Basin 3 (B3, Fig. 1), has recently been observed to accelerate (Dunse et al., 2012). Dowdeswell et al. (1999) reviewed evidence on the dynamics of B3 back to the 19th century. Presence of heavy crevassing was taken to indicate fast flow in the 1870s (Nordenskiold, 1875), whereas relatively smooth surface topography is thought to indicate stagnation in the 1980s (Dowdeswell et al., 1999). SAR (synthetic aperture radar) interferometry in the early 1990s shows flow speeds in 1992 and 1994 of up to $90 \mathrm{~m} \mathrm{a}^{-1}$ and $50 \mathrm{~m} \mathrm{a}^{-1}$ respectively over a cross section approximately $7.5 \mathrm{~km}$ upstream from the ocean margin (Dowdeswell et al., 1999). Ice velocity was of comparable magnitude in 1995 (Dunse et al., 2012) but has recently accelerated to give winter velocities up to $200 \mathrm{~m} \mathrm{a}^{-1}$ at locations similar to those where the 1992 and 1994 observations 
were made, and a velocity range (due to a strong seasonal cycle) near the margin of 300-700 $\mathrm{m} \mathrm{a}^{-1}$ (Dunse et al., 2012). In the current study we use an ice dynamic computer model to make inferences about basal properties and processes of B3 and its outlet glacier using recent satellite observations, and focus on the winter velocity increase rather than the seasonal cycle.

The fast flow of B3 is certainly due to basal sliding; ice deformation rarely accounts for more than $5 \mathrm{~m} \mathrm{a}^{-1}$ over Austfonna (Dowdeswell et al., 1999). This means that a purely ice dynamic model is not sufficient to simulate the velocity evolution of B3; some representation of the changing basal processes, which permit an increase in sliding, must be included.

A note on terminology: we use the term "sliding" to mean motion of the base of the glacier, irrespective of whether this is due to sliding of the glacier over its bed or deformation of underlying sediment. In the absence of a universally accepted definition of the term "surge" as applied to a glacier or ice stream, we utilise our own definition. By "surge-type" glacier we mean a coupled glacier-bed system showing strong (factor 3 or more) variability of ice velocity with a cyclic nature, independent of changes in external forcing (such as surface mass balance or temperature). By "surge" we mean the fast-flowing phase of a surge-type glacier during which the glacier shows rapid and sustained acceleration. We note that, by this fairly generic definition, different underlying mechanisms can lead to surge-type glaciers with a large range of periodicities and magnitudes.

Svalbard glaciers are known to be commonly (Jiskoot et al., 2000), or perhaps overwhelmingly, surge-type (Lefauconnier and Hagen, 1991; Sund et al., 2009). A Svalbard surge-type glacier typically spends several decades to a few centuries in a quiescent state, then becomes active for periods as long as a decade (Dowdeswell et al., 1991). The surge phase for Svalbard glaciers is significantly longer than for surging glaciers in other regions (Dowdeswell et al., 1991); however the relative increase of velocity during a surge is relatively lower than for glaciers in other regions. These facts may be linked: a slower-flowing surge phase would require a longer active period to discharge the same mass of ice. The longest surge phase listed by Dowdeswell et al. (1991) was for Bodleybreen on Vestfonna ice cap, which lasted for between 5 and $13 \mathrm{yr}$, with a best estimate of $7 \mathrm{yr}$. Surge speeds in Svalbard glaciers are typically many times greater than during the quiescent phase since sliding becomes the dominant component of ice flow. The speed of the B3 glacier in 1995 was much faster than is typical of the quiescent phase of Svalbard glaciers which do not slide, and, given the continued or accelerating velocity, suggests that the glacier has been in a fast-flowing or surging state for perhaps $20 \mathrm{yr}$, with an even faster state for the past few years. Given that B3 surface morphology indicated stagnant conditions most recently during in the 1980s, B3 may be experiencing an extremely long-lasting surge, or it may be an acceleration into a fast-flow regime that is not part of cyclic behaviour. In this respect B3 may be behaving more like an Antarctic ice stream where long-period slow-down and speed-up events occur, likely driven by changes in basal hydrology or "water piracy" (Tulaczyk et al., 2000; Anandakrishnan and Alley, 1997; Bougamont et al., 2011).

Svalbard surge-type glaciers are thought to be most commonly underlain by fine-grained and potentially deformable beds (Jiskoot et al., 2000). Although the importance of deformable sediment beneath glaciers was widely discussed in the literature of the 1980s (Boulton and Hindmarsh, 1987; Clarke, 1987a), ice dynamic modelling studies have only recently begun to simulate till deformation. Vieli and Gudmundsson (2010) model till as an incompressible non-linear viscous medium and do not consider the effects of hydrology. However, several studies (Tulaczyk et al., 2000; Clarke, 1987a; Iverson, 2010) show that sediment typically deforms plastically and that the yield stress is strongly dependent on effective pressure, which in turn is strongly dependent on water pressure and therefore also on hydrology.

Further modelling studies have investigated the impact of water content in deformable sediment on ice dynamics. Bougamont et al. (2011) solved a first-order differential equation for evolution of porosity in the till, and showed that, with a plastic bed model and a simple parameterisation for basal water availability, low-frequency oscillations could be obtained (of the order of $10^{3} \mathrm{yr}$ ) in an idealised ice sheet. Van Pelt and Oerlemans (2012) used a simple diffusion relation to simulate evolution of till water content and were able to demonstrate, for a plastic till (some of their simulations also included a small linearly viscous component), both lowfrequency oscillations (driven by changes in temperature distribution) and high-frequency oscillations (driven by changes in till water distribution) in an idealised outlet glacier, with till strength being an important factor governing possible oscillatory behaviour. van der Wel et al. (2013) used a plastic till model with a hydrology model that incorporates representation of channelised flow at the ice-till interface to demonstrate the important control that connectivity through to the grounding line exerts on upstream sliding.

These till studies all express yield stress as a function of one unknown, imposing dependency between effective pressure and porosity. Clarke (1987b) provides a physical framework based on soil studies in which both positive and negative dilatancy can occur, and the evolution of yield stress is a function of both porosity and effective pressure as independent variables.

Simulations incorporating plastic till deformation have not yet been applied to B3. However, Dunse et al. (2011) simulated cyclic behaviour on B3 using a basal drag formulation dependent on temperature and overburden pressure. Till water content is not explicitly simulated by Dunse et al. (2011), but may be implicit in the temperature dependency.

The current study does not attempt to simulate evolution of till properties, but instead uses inverse and transient 
simulations with an ice dynamic model to make inferences about key physical processes, which will in turn guide till model development. Section 2 presents a time series of three winter season inverse simulations whereby basal stress is derived to optimise the fit of simulated surface velocities to observations. Section 3.1 presents transient simulations as a sensitivity experiment to quantify the importance of omitting evolution of basal stress. Section 3.2 presents steadystate and transient simulations in which the thermodynamic regime of Basin 3 is investigated in order to inform the discussion on basal processes. Section 4 discusses possible feedback mechanisms to explain the acceleration of B3 in the light of the new simulations.

\subsection{Open-source tools}

A number of open-source software projects made possible the inverse modelling and other analyses in the current study. Elmer/Ice (Gagliardini et al., 2013) was used for ice dynamic simulations. Mesh generation for the simulations used YAMS (http://www.ann.jussieu.fr/ frey/publications/RT-0252.pdf) and GMSH (Geuzaine and Remacle, 2009). Analyses and presentation of outputs utilised Paraview (Ahrens et al., 2005).

\section{Inverse modelling}

Modelling results presented in the current study were obtained using the Elmer/Ice Stokes flow model for ice dynamics (Gagliardini et al., 2013). In this section, we present inverse simulations using the method of Arthern and Gudmundsson (2010) as implemented in Elmer/Ice by GilletChaulet et al. (2012). The experimental setup is the same as that used for neighbouring Vestfonna ice cap (Schäfer et al., 2013), following the work of Schäfer et al. (2012), except where stated otherwise.

\subsection{Model setup}

The approach to inverse modelling involves optimisation of the basal drag coefficient, $C$, to provide a best fit between observed and simulated surface velocities. $C$ is given by

$\tau_{\mathrm{b}}=C u_{\mathrm{b}}$,

where $\tau_{\mathrm{b}}$ is basal shear stress and $u_{\mathrm{b}}$ is basal ice velocity.

A three-step process is followed: the inversion is carried out with a uniform $\left(-7^{\circ} \mathrm{C}\right)$ temperature distribution; a steady-state temperature simulation is carried out using the velocities derived from the inversion; finally the inversion is repeated using the derived steady-state temperatures. This gives consistent temperature and velocity fields. The geometry is kept fixed at all stages. In some cases further temperature-inversion iterations were carried out, but these showed little or no further change. The steady-state tempera-

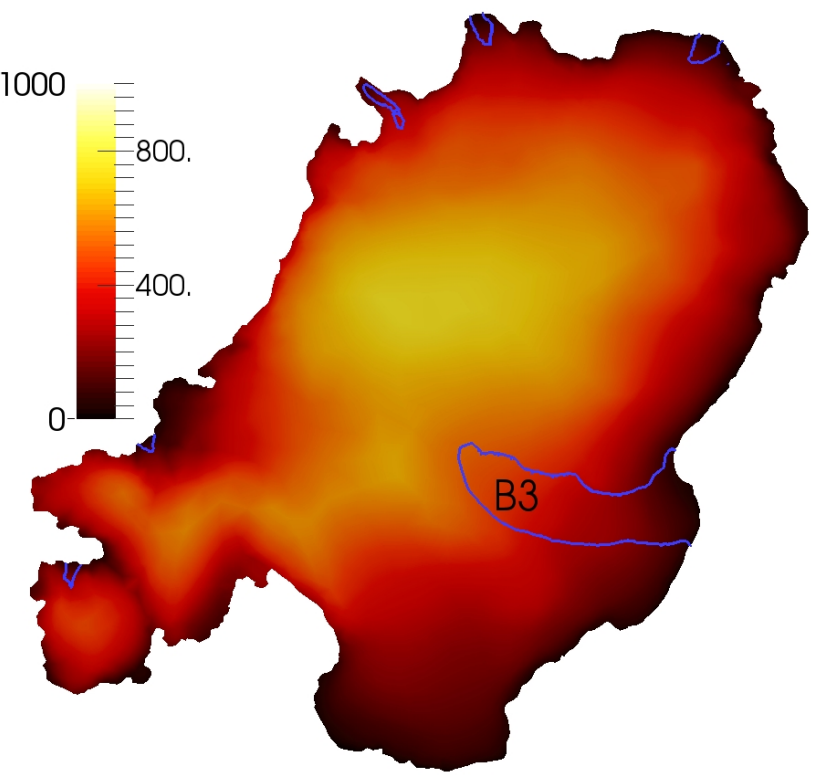

Figure 1. Surface height of the Austfonna ice cap. Fast-flowing outlet glaciers are indicated by the blue $100 \mathrm{~m} \mathrm{a}^{-1}$ contour calculated from 2011 observed velocities. The Basin 3 outlet glacier is labelled B3. North is towards the top of the figure.

ture simulation incorporates deformational heating and heating due to friction at the bed, as described by Schäfer et al. (2013).

The steady-state temperature simulation is carried out with a fixed-temperature boundary condition at the upper surface:

$T_{\mathrm{S}}=-7.684-0.004 z$,

where $T_{\mathrm{s}}$ is surface ice temperature, $z$ is height a.s.l. and the constant values on the right-hand side represent sea level temperature (in ${ }^{\circ} \mathrm{C}$ ) and lapse rate $\left(\right.$ in $^{\circ} \mathrm{C} \mathrm{m}^{-1}$ ) respectively, with values as in Schäfer et al. (2013).

A heat flux, $Q_{\mathrm{b}}$, boundary condition is used at the base of the ice:

$Q_{\mathrm{b}}=0.063+u_{\mathrm{b}} \tau_{\mathrm{b}}$,

where 0.063 is the geothermal heat flux and $u_{\mathrm{b}} \cdot \tau_{\mathrm{b}}$ is the frictional heat flux.

The ice geometry (surface elevation and bedrock heights) is based on Norwegian Polar Institute maps and various ice thickness data as described in Sect. 3.3 of Dunse et al. (2011). The surface elevation dates from 1990.

\subsubsection{Observed velocities}

Ice surface velocities based on satellite remote sensing are used. Velocities were obtained using radar interferometry for the period December 1995 to January 1996, offset tracking for the period January to March 2008 and a combined interferometry-tracking approach (effectively offset tracking 
over B3) for the period March to April 2011. A more detailed description is given below. It is important to emphasise that all these observations indicate velocities prior to the meltseason speed-up (Dunse et al., 2012).

Tandem Phase ERS-1/2 (European Remote Sensing Satellit) 1-day SAR scenes were acquired between December 1995 and January 1996 (1-day interval) and surface ice velocities were calculated using SAR interferometry (InSAR) (henceforth "1995 velocities"; Dowdeswell et al., 2008).

Four ALOS (Advanced Land Observing Satellite) PALSAR (Phased Array type L-band Synthetic Aperture Radar) scenes were acquired between January 2008 and March 2008 with a 46-day time interval and velocities calculated using offset tracking (henceforth "2008 velocities"; Pohjola et al., 2011).

For 2011, an ERS-2 SAR data stack acquired in March/April with a 3-day time interval processed with a combined InSAR and tracking approach is used (henceforth "2011 velocities"; Schäfer et al., 2013). In the northern and eastern parts of Austfonna, including B3, SAR data are available from only one orbit, and offset tracking was therefore considered.

In all three cases the vertical components of the velocities have been neglected during the calculation of horizontal velocities.

The displacement error in the InSAR data is about $2 \mathrm{~cm}$ (Dowdeswell et al., 2008), which corresponds to a velocity error of $7 \mathrm{~m} \mathrm{yr}^{-1}$ for Tandem ERS-1/2 SAR data (1-day time interval) and $2 \mathrm{~m} \mathrm{yr}^{-1}$ for 3-day ERS-2 SAR data. By considering a matching error estimate of $1 / 10$ of a pixel, the precision of offset tracking is about $10 \mathrm{~m} \mathrm{yr}^{-1}$ for the 2008 ALOS PALSAR data separated by a temporal interval of 46 days (Pohjola et al., 2011) and of the order of $130 \mathrm{~m} \mathrm{yr}^{-1}$ for the 2011 ERS-2 data set separated by a temporal interval of 3 days.

The 1995 data set of observed surface velocities, based on interferometry, is smooth and has good coverage (Dowdeswell et al., 2008). The 2008 and 2011 data sets contain many data gaps and regions with noisy error fields (Fig. 2). The dramatic speed-up of the B3 outlet glacier is of much greater magnitude than these errors, but the errors are such that, if there is a change in the slow-moving interior, it cannot be detected.

Since we wish to simulate the basal properties of B3 over time we need to provide a smooth input field for the inverse modelling. Therefore the following processing of the noisy velocity fields took place. The 2008 and 2011 velocities were smoothed using an 11-point (ca. $3 \mathrm{~km}$ ) conic filter. The B3 outlet glacier region from 2008 and 2011 was then copied over to the 1995 velocity field and smoothed using interpolation over a buffer zone, so that the smooth and complete 1995 data set can be used where data are missing or contain too much high-amplitude noise to be useful. This results in three data sets for inverse modelling, using 1995 velocities
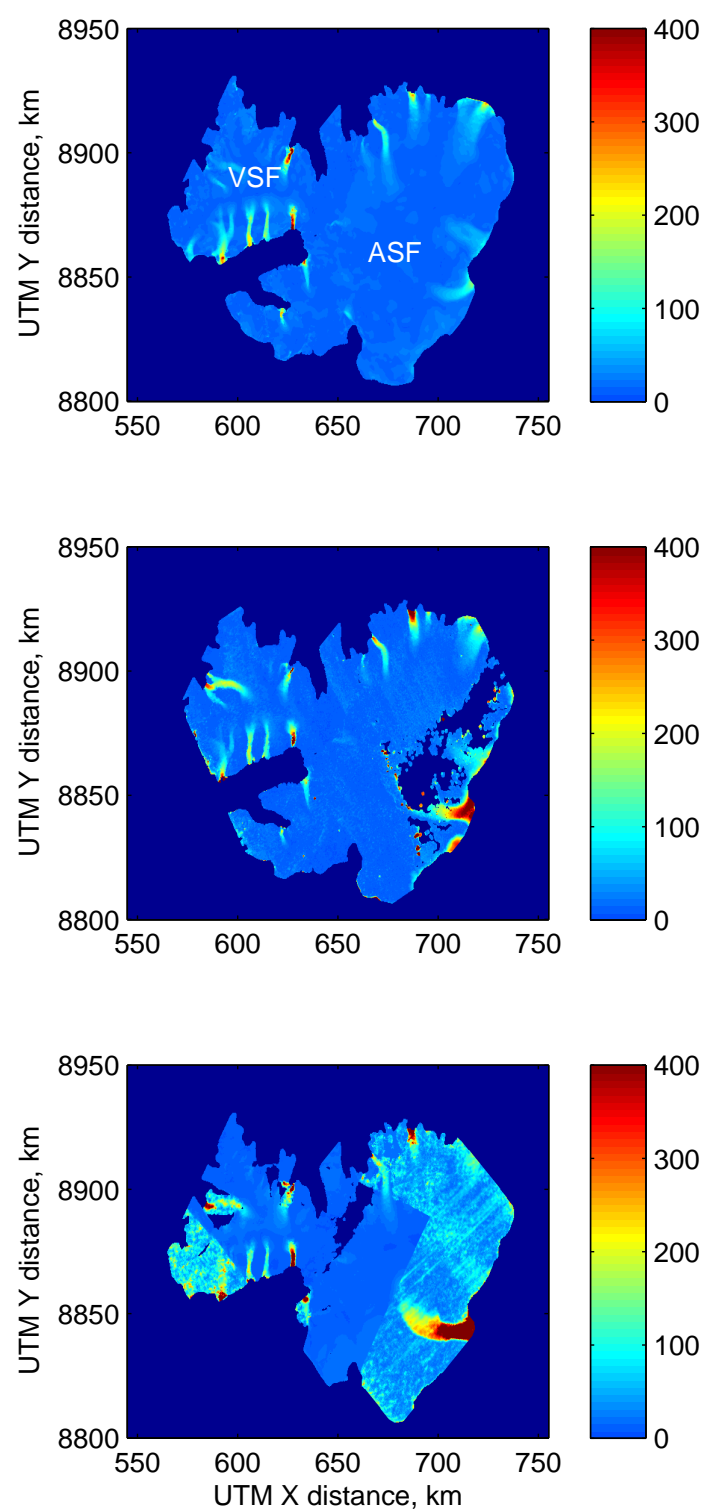

Figure 2. Observed winter velocity magnitude (in $\mathrm{m} \mathrm{a}^{-1}$ ) over Nordaustlandet from 1995 (top), 2008 (middle) and 2011 (bottom). B3 is the most prominent outlet glacier on the eastern side. Dark blue indicates no data. UTM zone is $33 \mathrm{~N}$. Neighbouring ice cap Vestfona (VSF) is also shown.

for regions other than B3, but with the 1995, 2008 and 2011 velocities respectively for the $\mathrm{B} 3$ region (Fig. 3 ).

\subsubsection{Mesh generation}

For consistency, all simulations in the current study use the same mesh (Fig. 4). The mesh is unstructured in the horizontal, and extruded in the vertical with 10 equally spaced layers. The horizontal mesh resolution varies between approximately $250 \mathrm{~m}$ and $2.5 \mathrm{~km}$. Mesh refinement is guided by 1995 velocity magnitude (smaller element size for higher 

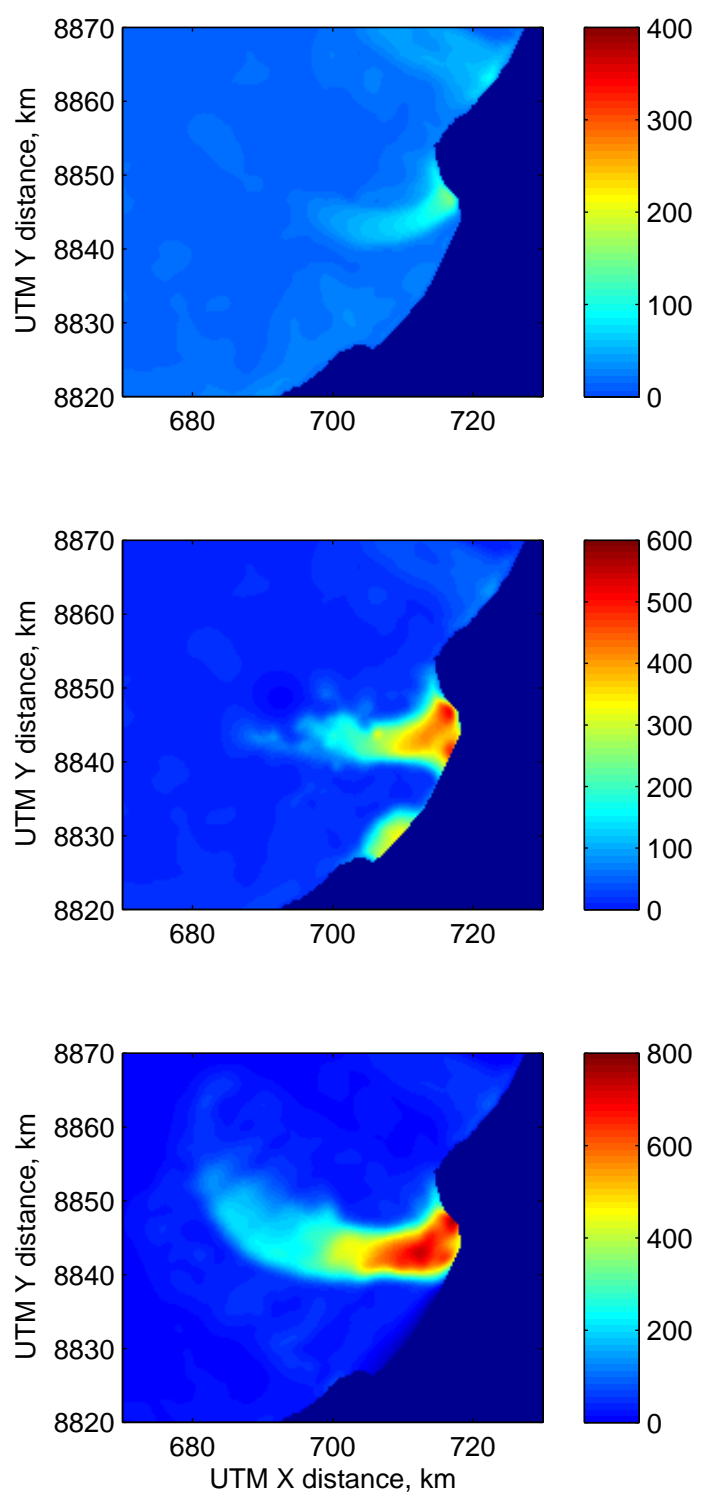

Figure 3. Smoothed and patched (see main text for details) observed winter velocity magnitude (in $\mathrm{m} \mathrm{a}^{-1}$ ) over B3, ASF, from 1995 (top), 2008 (middle) and 2011 (bottom). Note the different colour scales. Dark blue indicates no data. UTM zone is $33 \mathrm{~N}$.

velocities), except for B3. Mesh refinement for B3 is based on 2011 velocities with additional resolution enhancement.

Previous studies (Schäfer et al., 2013; Gillet-Chaulet et al., 2012) have implemented mesh refinement based on the Hessian of the velocity field in order to give a spatially uniform truncation error. Such an approach was not chosen for the current study due to the motivation to simulate greatly differing observed velocity fields on the same mesh, and to carry out transient simulations in which the velocity field is allowed to evolve.

\subsection{Inverse modelling results}

The simulated surface velocities for all three time periods show (unsurprisingly given the inverse approach) a good match to observations. The 1995- and 2011-simulated surface velocity fields are shown with the model mesh and the ice cap surface in Figs. 5a and c respectively. We present results from the 1995 and 2011 simulations, with 2008 providing a less significant intermediate state.

The basal drag coefficient $C$ is also shown in Figs. 5b and $\mathrm{d}$ for the 1995 and 2011 simulations respectively. Basal sliding accounts for most of the surface velocity (not shown). The $2011 C$ distribution shows, in comparison to the 1995 $C$, both a reduction in the minimum value of $C$ and an increase in the area of low $C$ corresponding to the increase in area of fast flow.

We compare the gravitational driving stress, $\tau_{\mathrm{D}}$, with the basal shear stress, $\tau_{\mathrm{b}}$, in Fig. 6. $\tau_{\mathrm{b}}$ is given by Eq. (1) and is dependent on the surface velocity observations, basal drag law, ice geometry and on shear stresses in the ice model. $\tau_{\mathrm{D}}$ is a function of the ice cap geometry only, and is given by

$\tau_{\mathrm{D}}=\rho g H \nabla(s)$,

where $\rho$ is ice density $\left(910 \mathrm{~kg} \mathrm{~m}^{-3}\right), g$ is gravitational acceleration $\left(9.81 \mathrm{~m} \mathrm{~s}^{-2}\right), H$ is ice thickness and $\nabla(s)$ is the ice surface gradient.

In $1995 \tau_{\mathrm{D}}$ is approximately 10 to $20 \mathrm{kPa}$ higher than $\tau_{\mathrm{b}}$ in the fast-flowing B3 outlet glacier, and is approximately the same amount lower than $\tau_{\mathrm{b}}$ at or just beyond the shear margins. This suggests that even in 1995 the bed strength is insufficient to balance the driving stress, and support from the lateral margins compensates. In 2011 the pattern is the same but stronger, with $\tau_{\mathrm{b}}$ dropping close to zero and $\tau_{\mathrm{D}}-\tau_{\mathrm{b}}$ around $50 \mathrm{kPa}$. The imbalance also occurs over a larger area (corresponding to the increased region of fast flow).

Note that $\tau_{\mathrm{D}}$ is calculated using the same ice cap geometry for different time periods. To test sensitivity of $\tau_{\mathrm{D}}$ to the evolving ice-cap-free surface we calculated $\tau_{\mathrm{D}}$ also using the ice cap geometry from the transient $T 11$ simulation (Sect. 3.1). The results (not shown) show very little difference to Fig. 6, because it is the change in $\tau_{\mathrm{b}}$ that dominates rather than the change in $\tau_{\mathrm{D}}$.

\section{Forward modelling}

Further simulations are carried out to investigate sensitivities to basal processes and to thermodynamic terms.

\subsection{Transient surface change experiment}

Two transient simulations of $100 \mathrm{yr}$ were carried out to compare the evolution of B3 when the 2011 basal drag is used (henceforth experiment T11) against the use of the 1995 basal drag (T95). The aim is an experiment to investigate 


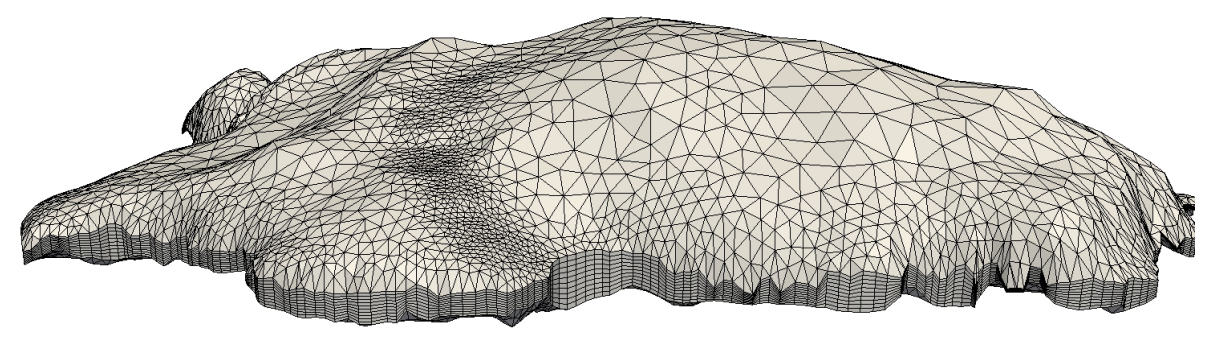

Figure 4. 3-D view of ASF showing the mesh refinement over the B3 outlet glacier, just left of centre. Vertical exaggeration is 30 times.
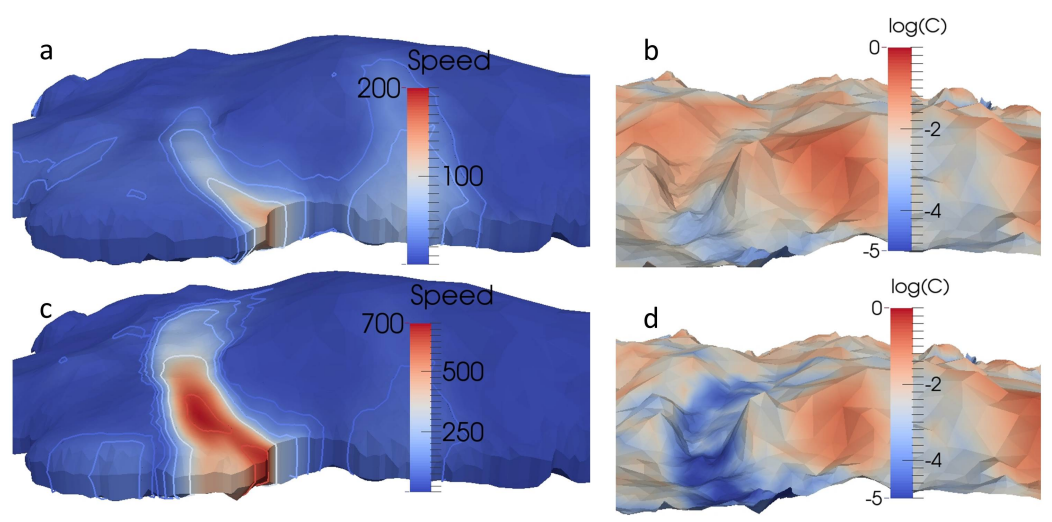

Figure 5. 3-D view (same viewing angle and vertical exaggeration as in Fig. 4) showing inverse model outputs in the B3 outlet glacier region. The left panels show simulated surface velocity magnitude (in $\mathrm{m} \mathrm{a}^{-1}$ ) in solid colour with observed velocity contours $(40,80,160,320$ and $640 \mathrm{~m} \mathrm{a}^{-1}$ ) overlain for (a) 1995 and (c) 2011. The right panels show the log of the basal drag coefficient, C, on the bedrock (the ice cap is removed) for (b) 1995 and (d) 2011. Units for C are MPa a m-1.

sensitivity of B3 evolution to basal drag; it is not a future prediction. Initialisation and forcing, described in the next two paragraphs, are approximately present day.

Initial ice cap geometry is as described in the setup for inverse modelling (Sect. 2). Temperature is given by the steady-state temperature derived using the inverse method for 1995. This temperature field is used for both T95 and $T 11$ experiments as we aim to isolate the impact of basal drag. Given that motion occurs primarily through sliding rather than deformation, temperature is held constant throughout the simulations.

Surface mass balance (SMB) is given by HIRHAM5, a regional atmospheric climate model (Christensen et al., 2007; Lucas-Picher et al., 2012). HIRHAM5 is based on the Undén et al. (2002) and ECHAM5 models (Roeckner et al., 2003), combining the dynamics of the former model with the physical parameterisation schemes of the latter. The physics of the model have been supplemented with a surface snow scheme and SMB calculation for glaciers (Mottram et al., 2014; Rae et al., 2012). SMB is calculated using the energy balance approach to determine melt rates and a parameterisation for retention of liquid water in the snowpack. The HIRHAM5 simulation used in this study was forced with the ECMWF ERAInterim reanalysis data set in the atmosphere and sea surface temperature and sea ice concentration also from the ECMWF for the period 1989-2011 (Langen et al., 2014). Bilinear interpolation is used to interpolate from the approximately $5 \mathrm{~km}$ resolution of HIRHAM5 to the finer-resolution Elmer mesh. The SMB does not evolve through time; rather the 1990s mean SMB is used. Surface temperature and geothermal heat flux are as described in Sect. 2.

Both simulations T95 and T11 show changes in surface elevation over much of the ice cap due to discrepancies between the divergence of the velocity field and the HIRHAM 1990s SMB. The T11 simulation shows a large (up to $1.8 \mathrm{~m} \mathrm{a}^{-1}$ ) relative surface lowering compared to T95 in the B3 interior (Fig. 7). The T11 simulation shows a thickening near the margin during the first two decades relative to the T95 simulation due to the greater discharge from the interior.

\subsection{Temperature simulations}

As discussed in the Introduction basal water pressure is a crucial factor governing sliding, and water cannot build up at the bed when the temperature is below pressure melting point (pmp). Here we present sensitivity studies to assess the relevance of different aspects of the thermodynamic regime, with a focus on which regions of the bed reach pmp. 

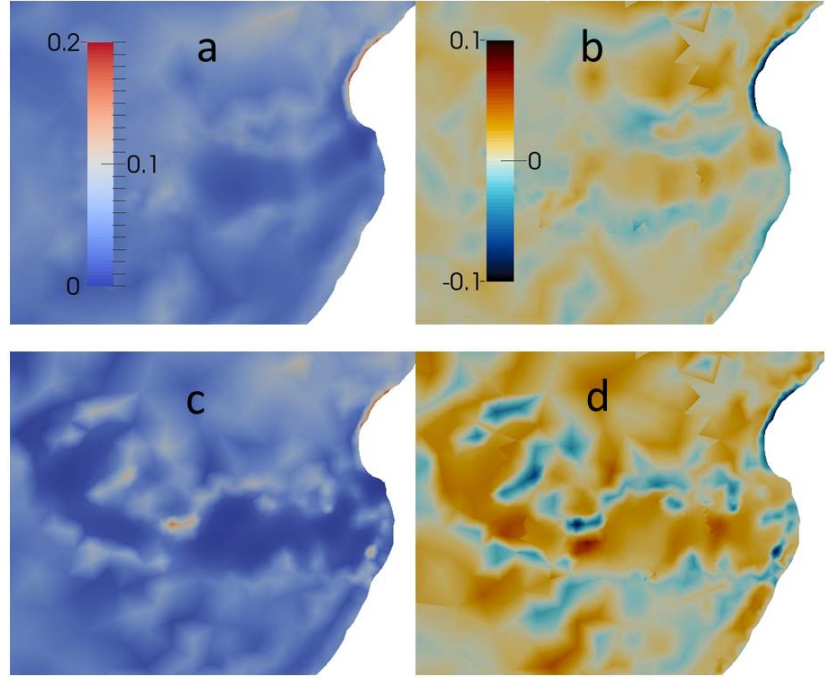

Figure 6. Basin 3 stress balance. Left: simulated basal shear stress $\left(\tau_{\mathrm{b}}\right)$ from the inverse modelling for (a) 1995 and (c) 2011. Right: gravitational driving stress (calculated from ice cap geometry) minus basal shear stress for (b) 1995 and (d) 2011. Note that the zigzag discontinuities visible in the plots on the right are artefacts of the parallel domain decomposition in a post-processing step and do not significantly affect the stress patterns. Units are MPa.

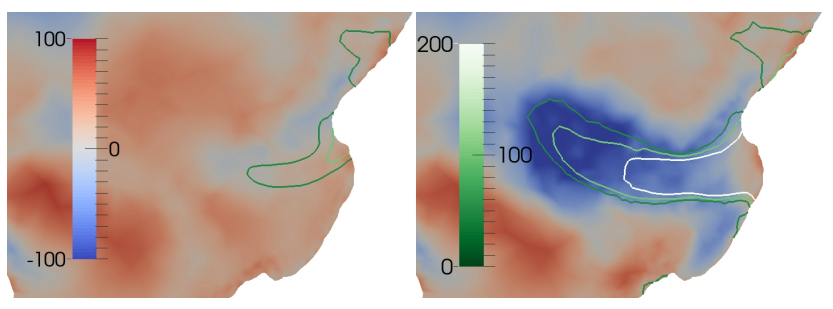

Figure 7. Change in free surface (in $\mathrm{m}$ ) over 100 model years using the 1995-derived basal drag field (simulation T95, left) and the 2011-derived basal drag field (simulation T11, right). Velocity contours (in $\mathrm{m} \mathrm{a}^{-1}$ ) are overlain to indicate regions of fast flow.

\subsubsection{Steady-state temperature simulations}

Here steady-state simulations are carried out to investigate the sensitivity of steady-state basal temperatures to geothermal heat flux, advection and frictional heat generation at the bed. The assumption of steady state is questionable for a surge-type glacier, and yet it provides an idealised starting point for sensitivity studies investigating thermodynamics.

A simulation with no advection terms (henceforth experiment SS for "steady state") was carried out as a proxy for 1980s basal temperatures. This simulation is repeated with geothermal heat flux, a poorly constrained parameter, halved from the value used in the T95 and T11 experiments to $31.5 \mathrm{~mW} \mathrm{~m}^{-2}$ (SSLG for "steady-state low geothermal heat flux"). These two experiments are designed such that the resulting temperature distribution is determined mainly by ver-
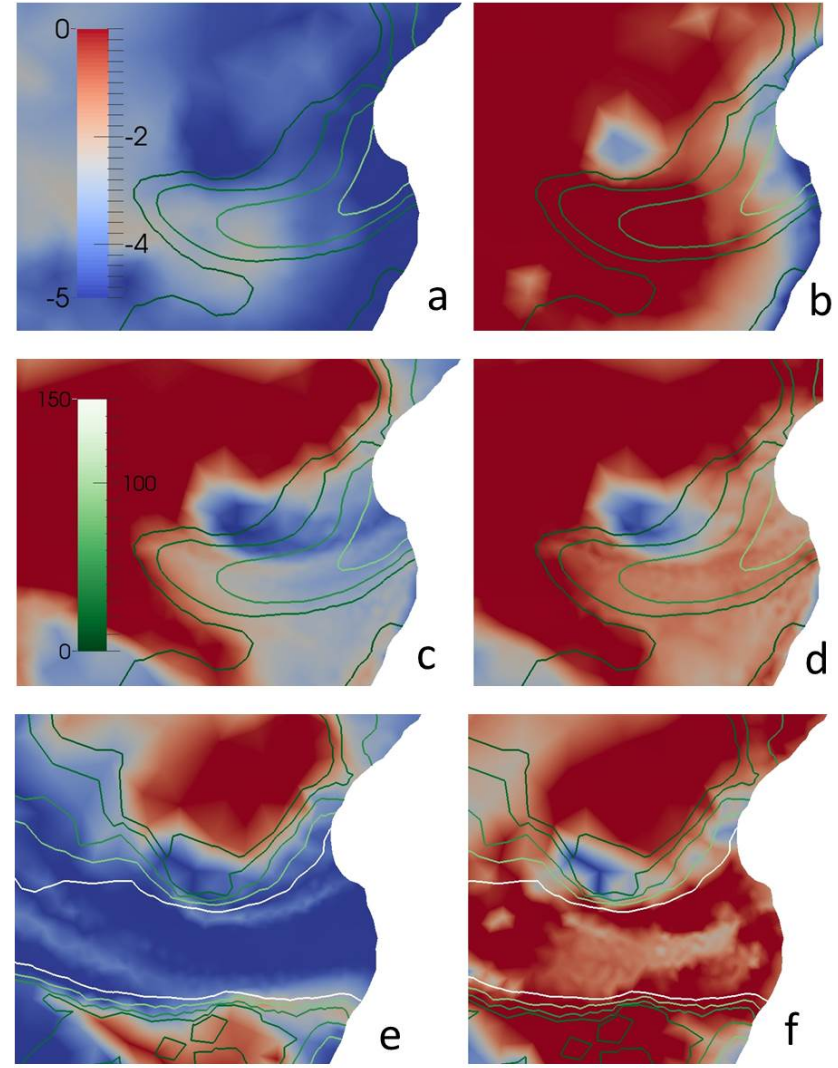

Figure 8. Basal temperatures (in centigrade relative to the pressure melting point) in the Basin 3 outlet glacier region from steady-state simulations described in Sect. 3.2.1: (a) diffusion only, geothermal heat flux halved (SSLG); (b) diffusion only (SS); (c) full thermodynamics with 1995 dynamical regime except that frictional heating is omitted (SS95NF); (d) full thermodynamics with 1995 dynamical regime (SS95); (e) full thermodynamics with 2011 dynamical regime except that frictional heating is omitted (SS11); and (f) full thermodynamics with 2011 dynamical regime (SS11NF). 1995 (a to d) and 2011 (e and f) velocity contours (in $\mathrm{m} \mathrm{a}^{-1}$ ) are overlain to indicate regions of fast flow.
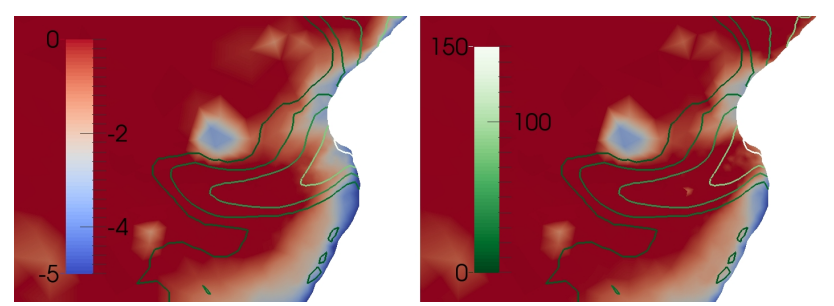

Figure 9. Basal temperatures (in centigrade relative to the pressure melting point) in the Basin 3 outlet glacier region from the transient simulation T_T95 after 10 years of integration (left) and 50 years (right). 1995 velocity contours (in $\mathrm{m} \mathrm{a}^{-1}$ ) are overlain to indicate regions of fast flow. 


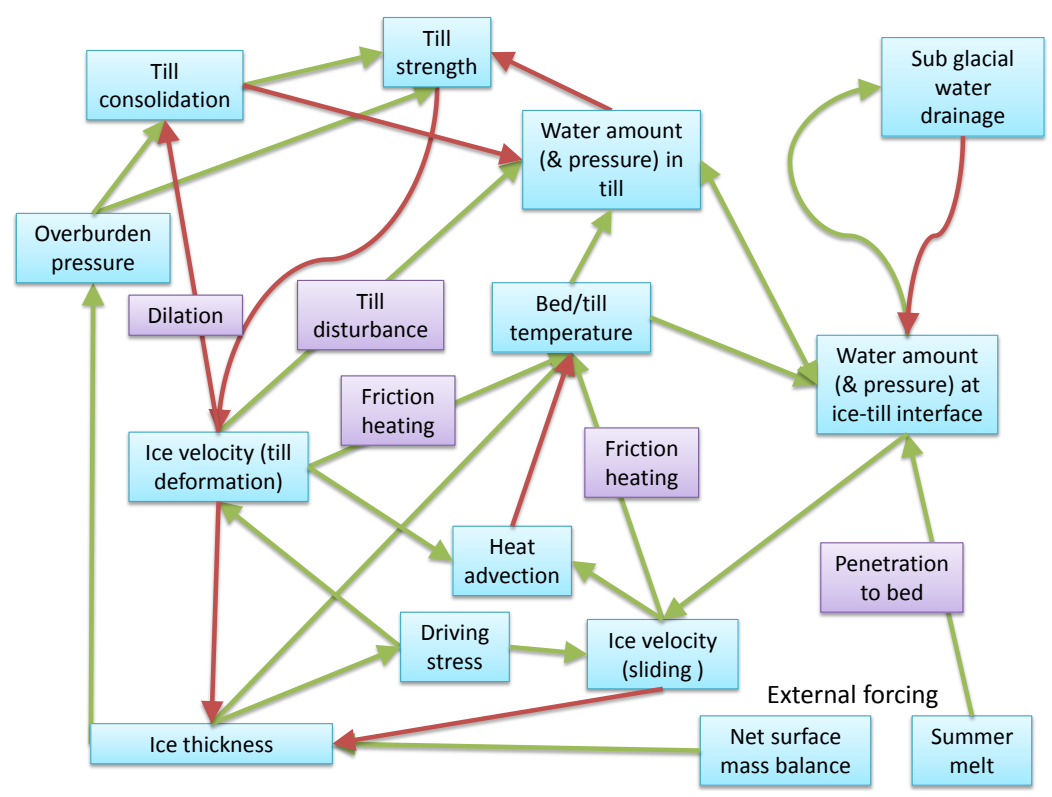

Figure 10. Properties (blue boxes) and processes (purple boxes) at the bed, and potential relationships/feedbacks between them. Red arrows indicate a decrease in the target property and green arrows indicate an increase. So a closed loop of arrows with an odd number of red arrows indicates a negative feedback, whereas a closed loop with an even number of (or zero) red arrows indicates a positive feedback. Note the "dilation" process could change to compression depending on the state of the till, changing the sign of the feedback.

tical diffusion. The SS simulation (Fig. 8b) shows a mostly temperate bed (i.e. at pressure melting point), with cold ice at the bed near the margins.

An ice mass in which the steady-state thermal regime is dominated by vertical diffusion has, for given surface and bed conditions, a hypothetical threshold thickness above which the steady-state bed temperature will be at pressure melting point, and below which the bed will remain below pressure melting point (decreasing monotonically with decreasing thickness). The facts that halving geothermal heat flux leads to a widespread cold bed under B3 (Fig. 8a) and that geothermal heat flux is poorly constrained (Schäfer et al. (2013) use $40 \mathrm{~mW} \mathrm{~m}^{-2}$, for example, on nearby Vestfonna) suggests that the present-day geometry of the ice cap is close to (likely just above) the thickness threshold for a temperate steady-state bed in the interior, and below the threshold near the margins.

In addition to a steady-state simulation with full thermodynamics using the 1995 simulated velocity and basal drag coefficient fields from the inversion (SS95, Fig. 8d), an identical simulation with frictional heating removed is carried out (SS95NF, Fig. 8c). Note that SS95 is identical (except for initial conditions) to the second step of the inversion process, Sect. 2. Compared to SS, SS95NF adds the effects of strain heating and heat advection. Similarly, steady-state temperature simulations with and without frictional heating at the bed were carried out using the 2011-simulated velocity and basal drag coefficient (simulations SS11 and SS11NF, Figs. 8e and $8 \mathrm{f}$ respectively). In SS95NF it can be seen that heat is ad- vected away from B3, and SS95 shows that even the presence of frictional heating does not compensate for advective heat loss in the steady state. The situation is different for 2011. As expected, the bed under the B3 outlet glacier is even colder in SS11 than in SS95 (due to the higher ice velocity), but the frictional heating more than compensates, resulting in temperate conditions under much of the B3 outlet glacier. This is due to high frictional heating in the shear margins and onset region.

This motivates the question of whether steady state is applicable to any of our time slices.

\subsubsection{Transient temperature simulation}

We carried out a transient simulation with full thermodynamics starting from the temperature distribution of the SS simulation, using the 1995 basal drag field. This simulation (T_T95) is identical to T95 except for the starting temperature distribution and the inclusion of thermodynamic evolution. T_T95 shows (Fig. 9) that on timescales of years to decades, advective heat loss plays a small role, with the bed remaining at pmp, and indeed the temperate region extending out towards the ocean.

The slow response time of advective heat loss certainly invalidates the steady-state assumption for B3 for any time period after 1995, when the velocity is known to be rapidly changing. The validity of the assumption in 1995 is also questionable. A likely scenario is that slow flow and gradual thickening of $\mathrm{B} 3$ occurred during the quiescent phase, 
resulting in a temperature distribution in 1995 somewhere between that of SS and a 100-year snapshot of T_T95.

However, the steady-state simulations are still informative. The simulations are consistent with much of the bed of the B3 interior and outlet glacier approaching pmp towards the end of the quiescent phase. The simulations indicate that, although advective heat loss and frictional heat generation are competing effects in terms of basal temperature, their net behaviour is not likely to reduce basal temperature below pmp during a surge. The implications of these temperature simulations are discussed further in Sect. 4.

\section{Discussion}

We discuss possible mechanisms for surging and whether the simulations presented here support them. Key properties of basal processes of glacier systems and their interactions are shown in Fig. 10 (see also Introduction). An outlet glacier for which (a subset of) these processes are active may or may not exhibit cyclic (surge) behaviour. Generation of till material and evolution of the grain size distribution are not considered here, but we include properties directly related to the hydrology of both the till and the ice-till interface, and also effects of ice cap geometry.

We consider which of these processes act to either restore or amplify a perturbation away from a steady state (or "attractor" in state space), in other words which processes act to return a glacier system towards steady state (negative feedbacks) or amplify the perturbation away from steady state (positive feedbacks). Note that in the context of internal periodicity, the attractor would likely be a hypothesised unstable steady state that lies within the periodic extremes. Any closed loop of processes in Fig. 10 indicates a feedback loop whose sign depends on the number of red arrows in the loop. Note that oscillations can arise from strongly non-linear negative feedbacks, or from positive feedbacks with a limited temporal effect, or from combinations of positive and negative feedbacks.

Ice thickness - driving stress feedback: ice thickening causes increased velocity due to increased driving stress. The combined increase in thickness and velocities increases the flux of ice discharged from the system, reducing ice thickness. This is a negative feedback, though it has previously been erroneously referred to as a positive feedback (Fowler et al., 2001).

Ice thickness - temperature feedback: thicker ice insulates the bed and allows warmer steady-state temperatures at the bed due to the warming effect of the geothermal heat flux. Warming at the bed increases the possibility of sliding, and the effective increase of heat generation at the bed potentially increases sliding velocity. This is a strongly non-linear (due to significance of the pressure melting point) long-timescale (heat diffuses slowly through ice) negative feedback that will tend to speed up a thick outlet glacier or slow down a thin outlet glacier.

These two negative feedback loops alone would be expected to lead either to a steady-state thickness profile in which SMB is exactly balanced by divergence of the ice flux, or long-timescale oscillations (order $10^{3}$ a) due to thermoviscous instability (Boulton and Hindmarsh, 1987; Fowler et al., 2001; Van Pelt and Oerlemans, 2012).

Efficient drainage feedback: the relationship between basal water and sliding is complicated, but the first-order response is an increase in sliding caused by increase in basal water. But increased basal water content also increases rate of discharge of water, reducing sliding. This is a highly non-linear negative feedback, with efficient drainage channels forming in response to high basal water content (Röthlisberger, 1972; Schoof, 2010). Such channels can drain basal water quickly, greatly reducing sliding velocities. Efficient drainage through channels is typically considered to be a hard-bed process, but if the timescale for water penetration of subglacial sediment is slow compared to the meltwater source (from in situ melting or penetration of surface melt) the process may also occur at the ice-till interface.

Frictional heating: friction due to either till deformation or sliding of ice over the bed causes heating and, where basal temperature is at the pressure melting point, increased melting, providing additional water to the till or ice-till interface. This decreases effective pressure, weakening till and enhancing flow speed (Iverson, 2010), providing a strong positive feedback to sliding velocity.

Advective heat loss: increased sliding increases advection of heat from the glacier to the ocean, potentially reducing basal temperatures below pmp. This provides a negative feedback to sliding velocity.

Water/till strength feedbacks: the interactions between deformation and till properties are complex. As stated above, increased water pressure leads to reduced till yield strength, making deformation more likely. However, deformation can lead to either dilation (which weakens the till) or compression (which strengthens the till). Dilation is the expansion (and thus the increase in the porosity) of consolidated till in response to shearing. Dilatancy decreases with effective pressure and porosity (Clarke, 1987b). This is further complicated by water availability. If insufficient water is available, then dilation can strengthen instead of weaken the till due to decreasing water pressure as porosity increases (Iverson, 2010). This network of dependencies is hard to resolve without a detailed model for till evolution.

We argue against a hard-bedded sliding mechanism. B3 exhibits seasonal cyclicity in addition to the ongoing (interannual) speed-up (Dunse et al., 2012). The only plausible mechanism for seasonality is due to surface meltwater reaching the bed and causing basal motion due to either sliding at the ice-till interface or till deformation. The reduction in velocity after the melt season can only be due to drainage of the excess basal water, most likely through efficient drainage 
channels. If both the seasonal speed-up and the interannual acceleration are due to hard-bedded sliding, it is hard to explain why the additional water needed for the interannual acceleration is not discharged by the same method as the seasonal acceleration after the melt season. The possibility that seasonal acceleration occurs due to sliding near the ice cap margin whereas interannual acceleration occurs due to upstream water build-up can be discounted due to the similar spatial patterns of both types of acceleration (Dunse et al., 2012).

We therefore hypothesise that the seasonal cycle is governed by the evolution of hydrology at the ice-till interface in response to penetration of surface melt, and that the interannual acceleration is governed by evolving by till properties, of which porosity, water pressure and permeability are perhaps the most important. This is consistent with previous studies that point to soft-bed mechanisms for some Svalbard glacier surges (Dowdeswell et al., 1999; Jiskoot et al., 2000; Murray et al., 2003). The physical separation of the seasonal and interannual accelerations could be due to the difference in timescales: seasonal melt events may be too short in duration for water to percolate into the sediment and may instead form drainage channels at the ice-till interface. In this case it is likely that, while much of the seasonal melt water drains into the ocean, a fraction will percolate into, and be stored within, the till, contributing to the ongoing surge build-up.

Reality may not be so simple: "sticky" spots (bedrock rises protruding through the sediment (Fowler et al., 2001)) may become important once $\tau_{\mathrm{b}}$ has passed the yield stress.

There is some evidence to suggest a positive total mass balance over the accumulation zone of ASF in the late 20th century (Bevan et al., 2007), but this may be attributable to surge-type basins in quiescent phase rather than being indicative of a climate-forced increase in SMB.

The 2000s in Svalbard were likely warmer than any period in the previous $1000 \mathrm{yr}$ (Grinsted et al., 2006; Virkkunen et al., 2007; Divine et al., 2011). Dunse et al. (2009) identify a high amount of surface melt over the southern part of ASF in summer 2004, followed by lowering of the firn line and increase in SMB until 2007 (see also Moholdt et al. (2010)).

\subsection{Implications of modelling results}

Given the likelihood that ASF overlies a plastically deformable till, we consider the significance of our basal stress calculations from the inverse simulations (Fig. 6). The relatively small and uniform excess of $\tau_{\mathrm{D}}$ over $\tau_{\mathrm{b}}$ in 1995 suggests that the till may already be starting to fail, but that $\tau_{\mathrm{D}}$ is still close to the till yield stress, with the larger difference seen in 2011 suggesting widespread till failure. Given that changes in $\tau_{\mathrm{D}}$ between 1995 and 2011 are relatively small (Sect. 2), this implies a reduction in the till yield strength, most likely caused by an increase in pore water pressure and or porosity (i.e. dilation) in the till. Pore water pressure in- crease is consistent with an increase in water production at the bed resulting from the frictional heating feedback.

The high spatial variability in modelled basal stress arises from small-scale spatial variations in the velocity field. These may be due to the presence of sticky spots. However given the noisy error fields associated with the observed 2011 velocities, they may be artefacts of measurement errors.

A prerequisite for rapid sliding is a temperate bed. The temperature simulations (Sect. 3.2) are consistent with a gradual thickening during the quiescent phase, leading to temperate conditions at the bed in the B3 interior. We now consider mechanisms for the temperate bed extending to the margin.

The onset of surge behaviour in some glaciers has been observed to occur through downstream propagation of a surge front between fast-moving temperate-based ice upstream and slow-flowing cold-based ice downstream. The two key characteristics of a surge front are the transition between a cold bed and a warm bed, and a significant steepening of the surface slope (Fowler et al., 2001; Murray et al., 1999). A propagating surge front seems unlikely for B3 for several reasons: it has been suggested that surge front propagation is more typical of land-terminating glaciers than marine-terminating glaciers (Murray et al., 2003). In 1995 the higher velocities were towards the front, suggesting that any propagating surge front would have to have developed before this time, but with velocities in 1995 of the order of $100 \mathrm{~m} \mathrm{yr}^{-1}$ we would argue that the surge was not underway at this time. The steepening of surface slope at the surge front, which provides the high driving stresses needed to propagate the surge front into the cold-bedded region, would be much harder to achieve (i.e. a much greater volume of ice would $b$ required) for a lowaspect-ratio glacier like B3 (the aspect ratio of B3 is nearly an order of magnitude lower than that of Bakaninbreen, for example (Murray et al., 1999), on which surge front propagation has been observed). Therefore we consider surge front propagation to be unlikely, though not impossible, for B3.

The temperature simulations suggest that, while a fastflowing outlet glacier would be expected to advect sufficient heat away to lower the temperature in some regions below pmp, a slow-flowing outlet glacier might advect heat towards the margins without causing the interior to become cold based (at least not for many decades). We therefore hypothesise a quiescent phase with a slow-flowing outlet glacier and a gradual increase of thickness. As the ice thickens the interior becomes temperate, and this temperate region is gradually extended to the ice front through a combination of heat advection and continued thickening.

Once a temperate bed is obtained throughout the outlet glacier, water pressure can increase, leading to rapid sliding, and the frictional heat feedback becoming important. This mechanism could potentially occur locally rather than under the whole outlet glacier, in which case the resistive stress would be transferred to nearby cold-bedded regions by longitudinal stress in the ice. In order for this to lead to locally 
rapid sliding, high driving stresses would be needed to overcome the lateral resistance. While the B3 driving stress is low due to the low aspect ratio, this may provide the mechanism for surge front propagation in steeper glaciers.

As the till begins to fail, the basal shear stress drops, reducing frictional heating and transferring the resistive stress to the shear margins. The higher friction under the shear margins, and the higher heating due to internal ice deformation in this region, could lead to increased basal water generation under the shear margins, leading to preferential weakening of the bed below the shear margins more than the main trunk. This provides a possible mechanism for the observed (Fig. 3) widening of the outlet glacier through shear margin migration.

Temperate conditions throughout the B3 outlet glacier allow redistribution of heat (and possible heat loss to the ocean) through the subglacial hydrological system (this process is not currently represented in our simulations). The reduction in frictional heating due to a failing till, and heat loss to the ocean due to both ice advection and hydrological discharge, could jointly contribute to eventual colder-bed conditions and surge shutdown. Dynamic thinning of the glacier could also lead to basal temperature reduction through reduced insulation against the cooler atmosphere, but this would be on a timescale longer than decades, and is hence an unlikely candidate for a surge shutdown mechanism.

\section{Conclusions}

We have conducted simulations to demonstrate that the assumption of a linear relationship between basal drag and basal velocity, along with a temporally fixed coefficient, can lead to large errors in simulations of ice cap evolution.

The proposed soft-bed surge mechanism of Fowler et al. (2001) is likely applicable to Austfonna's Basin 3, with the addition of a seasonal cycle arising from surface melt reaching the ice-till interface and then draining through efficient drainage channels, without ever penetrating significantly into the sediment.

Our simulations are consistent with this theory, and also suggest that the increase in advection of heat due to sliding is likely to limit the duration of the surge phase of Basin 3 . Observations and simulations are consistent with a quiescent phase ending in the 1990s, with rapid acceleration occurring in the 2000s.

Arguments presented here, and in previous studies, point to the importance of incorporating basal processes into future models of glacier systems in which sliding may occur, and suggest that hydrology is key for sliding on both hard and soft beds. Models of surge-type glaciers should be able to simulate subglacial hydrology, including residence times and water routing, and its impact on bed yield strength. In particular, modelling the interaction between sediment properties and water pressure evolution is essential in order sep- arate internal cyclicity from climatic forcing and to predict future behaviour of Austfonna.

Acknowledgements. We wish to thank Thorben Dunse from the University of Oslo for providing bedrock and surface elevation data. The satellite velocity data were produced with support of the EU FP6 INTEGRAL Project (1995), the ESA DUE GLOBGLACIER Project (2008) and the EU FP7 CRYOLAND Project (2011). We wish to thank Fabien Gillet-Chaulet from the Université Joseph Fourier for making available his code for the inverse modelling. We acknowledge CSC - IT Center for Science Ltd. for the allocation of computational resources. This work was performed at the Arctic Centre at the University of Lapland through funding by projects SVALI (Stability and Variations of Arctic Land Ice) and SvalGlac. This publication is contribution number 31 of the Nordic Centre of Excellence SVALI funded by the Nordic Top-level Research Initiative.

Edited by: M. Sharp

\section{References}

Ahrens, J., Geveci, B., and Law, C.: 36 - ParaView: An EndUser Tool for Large-Data Visualization, in: Visualization Handbook, edited by Hansen, C. D. and Johnson, C. R., 717 pp. LXXII, Butterworth-Heinemann, Burlington, doi:10.1016/B978012387582-2/50038-1, 2005.

Anandakrishnan, S. and Alley, R.: Stagnation of ice stream C, West Antarctica by water piracy, Geophys. Res. Lett., 24, 265-268, doi:10.1029/96GL04016, 1997.

Arthern, R. J. and Gudmundsson, G. H.: Initialization of ice-sheet forecasts viewed as an inverse Robin problem, J. Glaciol., 56, 527-533, 2010.

Bevan, S., Luckman, A., Murray, T., Sykes, H., and Kohler, J.: Positive mass balance during the late 20th century on Austfonna, Svalbard, revealed using satellite radar interferometry, in: Ann. Glaciol., VOL 46, 2007, edited by Sharp, M, vol. 46 of Ann. Glaciol., pp. 117-122, Int Glaciol Soc; British Antarct Res; IUGG Commiss Cryospher Sci; World Climate Res Program Climate \& Cryosphere Project, Int Glaciological Soc, Lensfield rd, Cambridge CB2 1ER, England, doi:10.3189/172756407782871477, International Symposium on Cryospheric Indicators of Global Climate Change, Cambridge, England, 21-25 August, 2006, 2007.

Bougamont, M., Price, S., Christoffersen, P., and Payne, A. J.: Dynamic patterns of ice stream flow in a 3-D higher-order ice sheet model with plastic bed and simplified hydrology, J. Geophys. Res.-Earth Surf., 116, F04018, doi:10.1029/2011JF002025, 2011.

Boulton, G. and Hindmarsh, R.: Sediment deformation beneath glaciers - rheology and geological consequences, J. Geophys. Res.-Solid Earth Planets, 92, 9059-9082, doi:10.1029/JB092iB09p09059, 1987.

Christensen, O., Drews, M., Christensen, J., Dethloff, K., Ketelsen, K., Hebestadt, I., and Rinke, A.: The HIRHAM regional climate model version $5(\beta)$. Danish Meteorological Institute Technical Report 06-17, http://www.dmi.dk/fileadmin/Rapporter/TR/ tr06-17.pdf, 2007. 
Clarke, G.: Fast glacier flow - ice streams, surging, and tidewater glaciers, J. Geophys. Res.-Solid Earth Planets, 92, 8835-8841, doi:10.1029/JB092iB09p08835, 1987a.

Clarke, G.: Subglacial till - a physical framework for its properties and processes, J. Geophys. Res.-Solid Earth Planets, 92, 90239036, doi:10.1029/JB092iB09p09023, 1987b.

Divine, D., Isaksson, E., Martma, T., Meijer, H. A. J., Moore, J., Pohjola, V., van de Wal, R. S. W., and Godtliebsen, F.: Thousand years of winter surface air temperature variations in Svalbard and northern Norway reconstructed from ice-core data, Polar Research, 30, 7379, doi:10.3402/polar.v30i0.7379, 2011.

Dowdeswell, J., Hamilton, G., and Hagen, J.: The duration of the active phase on surge-type glaciers - contrasts between Svalbard and other regions, J. Glaciol., 37, 388-400, 1991.

Dowdeswell, J., Unwin, B., Nuttall, A., and Wingham, D.: Velocity structure, flow instability and mass flux on a large Arctic ice cap from satellite radar interferometry, Earth Planet. Sci. Lett., 167, 131-140, doi:10.1016/S0012-821X(99)00034-5, 1999.

Dowdeswell, J. A., Benham, T. J., Strozzi, T., and Hagen, J. O.: Iceberg calving flux and mass balance of the Austfonna ice cap on Nordaustlandet, Svalbard, J. Geophys. Res.-Earth Surf., 113, F03022, doi:10.1029/2007JF000905, 2008.

Dunse, T., Schuler, T. V., Hagen, J. O., Eiken, T., Brandt, O., and Hogda, K. A.: Recent fluctuations in the extent of the firn area of Austfonna, Svalbard, inferred from GPR, Ann. Glaciol., 50, 155-162, doi:10.3189/172756409787769780, 2009.

Dunse, T., Greve, R., Schuler, T. V., and Hagen, J. O.: Permanent fast flow versus cyclic surge behaviour: numerical simulations of the Austfonna ice cap, Svalbard, J. Glaciol., 57, 247-259, 2011.

Dunse, T., Schuler, T. V., Hagen, J. O., and Reijmer, C. H.: Seasonal speed-up of two outlet glaciers of Austfonna, Svalbard, inferred from continuous GPS measurements, The Cryosphere, 6, 453466, doi:10.5194/tc-6-453-2012, 2012.

Fowler, A., Murray, T., and Ng, F.: Thermally controlled glacier surging, J. Glaciol., 47, 527-538, doi:10.3189/172756501781831792, 2001.

Gagliardini, O., Zwinger, T., Gillet-Chaulet, F., Durand, G., Favier, L., de Fleurian, B., Greve, R., Malinen, M., Martín, C., Råback, P., Ruokolainen, J., Sacchettini, M., Schäfer, M., Seddik, H., and Thies, J.: Capabilities and performance of Elmer/Ice, a new generation ice-sheet model, Geosci. Model Dev. Discuss., 6, 16891741, doi:10.5194/gmdd-6-1689-2013, 2013.

Geuzaine, C. and Remacle, J.-F.: Gmsh: A 3-D finite element mesh generator with built-in pre- and post-processing facilities, Int. J. Numer. Meth. Eng., 79, 1309-1331, doi:10.1002/nme.2579, 2009.

Gillet-Chaulet, F., Gagliardini, O., Seddik, H., Nodet, M., Durand, G., Ritz, C., Zwinger, T., Greve, R., and Vaughan, D. G.: Greenland ice sheet contribution to sea-level rise from a newgeneration ice-sheet model, The Cryosphere, 6, 1561-1576, doi:10.5194/tc-6-1561-2012, 2012.

Grinsted, A., Moore, J., Pohjola, V., Martma, T., and Isaksson, E.: Svalbard summer melting, continentality, and sea ice extent from the Lomonosovfonna ice core, Journal of Geophysical ResearchAtmospheres, 111, doi:10.1029/2005JD006494, 2006.

Iverson, N. R.: Shear resistance and continuity of subglacial till: hydrology rules, J. Glaciol., 56, 1104-1114, 2010.
Jiskoot, H., Murray, T., and Boyle, P.: Controls on the distribution of surge-type glaciers in Svalbard, J. Glaciol., 46, 412-422, doi:10.3189/172756500781833115, 2000.

Langen, P., Mottram, R. H., Christensen, J. H., Boberg, F., Rodehacke, C., Stendel, M., Cappelen, J., van As, D., Ahlstrøm, A., Mortensen, J., Rysgaard, S., Petersen, D., Svendsen, S. H., and Adalgeirsdottir, G.: Estimating and understanding recent changes in freshwater input to the Godthåbsfjord, Greenland, using a high-resolution regional climate model, in preparation, 2014.

Lefauconnier, B. and Hagen, J.: Surging and calving glaciers in Eastern Svalbard, Norsk Polarinstitutt Meddelelser, 1-130, 1991.

Lucas-Picher, P., Wulff-Nielsen, M., Christensen, J. H., Adalgeirsdottir, G., Mottram, R., and Simonsen, S. B.: Very high resolution regional climate model simulations over Greenland: Identifying added value, J. Geophys. Res.-Atmos., 117, D02108, doi:10.1029/2011JD016267, 2012.

Moholdt, G., Hagen, J. O., Eiken, T., and Schuler, T. V.: Geometric changes and mass balance of the Austfonna ice cap, Svalbard, The Cryosphere, 4, 21-34, doi:10.5194/tc-4-21-2010, 2010.

Mottram, R., Adalgeirsdottir, G., Boberg, F., Lucas-Picher, P., Stendel, M., Christensen, O. B., and Christensen, J. H.: Reconstructing the Surface Mass Budget of the Greenland Ice Sheet with the Regional Climate Model HIRHAM5 1989-2011, in preparation, 2014.

Murray, T., Strozzi, T., Luckman, A., Jiskoot, H., and Christakos, P.: Is there a single surge mechanism? Contrasts in dynamics between glacier surges in Svalbard and other regions, J. Geophys. Res.-Solid Earth, 108, 15, doi:10.1029/2002jb001906, 2003.

Murray, T., Dowdeswell, J. A., Drewry, D. J., Frearson, I: Geometric evolution and ice dynamics during a surge of Bakaninbreen, Svalbard, J. Glaciol., 44, 263-272, 1998.

Nordenskiold, E.: Den Svenska Polarexpeditionen, 1872-73, Svenska Vetenskapsakademiets Handlingar 2, 1875.

Pohjola, V. A., Christoffersen, P., Kolondra, L., Moore, J. C., Pettersson, R., Schafer, M., Strozzi, T., and Reijmer, C. H.: Spatial distribution and change in the surface ice-velocity field of Vestfonna ice cap, Nordaustlandet, Svalbard, 19952010 using geodetic and satellite interferometry data, Geograf. Ann. Se. A-Phys. Geogr., 93A, 323-335, doi:10.1111/j.14680459.2011.00441.x, 2011.

Rae, J. G. L., Aoalgeirsdottir, G., Edwards, T. L., Fettweis, X., Gregory, J. M., Hewitt, H. T., Lowe, J. A., Lucas-Picher, P., Mottram, R. H., Payne, A. J., Ridley, J. K., Shannon, S. R., van de Berg, W. J., van de Wal, R. S. W., and van den Broeke, M. R.: Greenland ice sheet surface mass balance: evaluating simulations and making projections with regional climate models, The Cryosphere, 6, 1275-1294, doi:10.5194/tc-6-1275-2012, 2012.

Roeckner, E., Bäuml, G., Bonaventura, L., Brokopf, R., Esch, M., Giorgetta, M., Hagemann, S., Kirchner, I., Kornblueh, L., Manzini, E., Rhodin, A., Schlese, U., Schulzweida, U., and Tompkins, A.: The atmospheric general circulation model ECHAM5. Part 1. Model description. Report no. 349, MaxPlanck-Institut für Meteorologie (MPI-M), 2003.

Röthlisberger, H.: Water pressure in intra and subglacial channels, J. Glaciol., 11, 177-203, 1972.

Schäfer, M., Gillet-Chaulet, F., Gladstone, R., Pettersson, R., Pohjola, V. A., Strozzi, T., and Zwinger, T.: Assessment of heat sources on the control of fast flow of Vestfonna Ice Cap, Sval- 
bard, The Cryosphere Discuss., 7, 5097-5145, doi:10.5194/tcd7-5097-2013, 2013.

Schäfer, M., Zwinger, T., Christoffersen, P., Gillet-Chaulet, F., Laakso, K., Pettersson, R., Pohjola, V. A., Strozzi, T., and Moore, J. C.: Sensitivity of basal conditions in an inverse model: Vestfonna ice cap, Nordaustlandet/Svalbard, The Cryosphere, 6, 771783, doi:10.5194/tc-6-771-2012, 2012.

Schoof, C.: Ice-sheet acceleration driven by melt supply variability, Nature, 468, 803-806, doi:10.1038/nature09618, 2010.

Sund, M., Eiken, T., Hagen, J. O., and Kaab, A.: Svalbard surge dynamics derived from geometric changes, Ann. Glaciol., 50, 5060, 2009.

Tulaczyk, S., Kamb, W., and Engelhardt, H.: Basal mechanics of Ice Stream B, West Antarctica 1. Till mechanics, J. Geophys. Res.Solid Earth, 105, 463-481, doi:10.1029/1999JB900329, 2000.

Undén, P., Rontu, L., Järvinen, H., Lynch, P., Calvo, J., Cats, G., Cuxart, J., Eerola, K., Fortelius, C., Garcia-Moya, J. A., Jones, C., Lenderlink, G., McDonald, A., McGrath, R., Navascues, B., Woetman Nielsen, N., Ødegaard, V., Rodrigues, E., Rummukainen, M., Rõõm, R., Sattler, K., Hansen Sass, B., Savijärvi, H., Wichers Schreur, B., Sigg, R., The, H., and Tijm, A.: HIRLAM-5 Scientific Documentation, http://hirlam.org, 2002. van der Wel, N., Christoffersen, P., and Bougamont, M.: The influence of subglacial hydrology on the flow of Kamb Ice Stream, West Antarctica, J. Geopys. Res., 118, 97-110, doi:10.1029/2012JF002570, 2013.

Van Pelt, W. J. J. and Oerlemans, J.: Numerical simulations of cyclic behaviour in the Parallel Ice Sheet Model (PISM), J. Glaciol., 58, 347-360, doi:10.3189/2012JoG11J217, 2012.

Vieli, G. J. M. C. L. and Gudmundsson, G. H.: A numerical study of glacier advance over deforming till, The Cryosphere, 4, 359-372, doi:10.5194/tc-4-359-2010, 2010.

Virkkunen, K., Moore, J. C., Isaksson, E., Pohjola, V., Peramaki, P., Grinsted, A., and Kekonen, T.: Warm summers and ion concentrations in snow: comparison of present day with Medieval Warm Epoch from snow pits and an ice core from Lomonosovfonna, Svalbard, J. Glaciol., 53, 623-634, doi:10.3189/002214307784409388, 2007. 